\title{
Complexidade, interdisciplinaridade e saber ambiental ${ }^{\star}$
}

\section{Complexity, interdisciplinarity and environmental knowledge}

Enrique Leff**

Resumo: O artigo se propõe a realizar uma reflexão crítica sobre os marcos conceituais e as bases epistemológicas da questão ambiental, os quais podem impulsionar uma prática da interdisciplinaridade mais aprofundada e bem fundamentada em seus princípios teóricos e metodológicos, orientada ao manejo, gestão e apropriação dos recursos ambientais.

Palavras-chave: Complexidade. Formação ambiental. Interdisciplinaridade. Saber ambiental.

Abstract: This article proposes to undertake a critical reflection on the conceptual frameworks and the epistemological basis of environmental issues, which can stimulate an interdisciplinary practice that is more in-depth and well-grounded in theoretical and methodological principles and is more aimed at management and the ownership of environmental resources.

Keywords: Complexity. Environmental training. Interdisciplinarity. Environmental knowledge.

\section{Interdisciplinaridade e formação ambiental: antecedentes $\mathrm{e}$ contribuições da América Latina}

A questão ambiental, com a sua complexidade, e a interdisciplinaridade emergem no último terço do século XX (finais dos anos 60 e começo da década de 70) como problemáticas contemporâneas, compartilhando o sintoma de uma crise de civilização, de uma crise que se manifesta pelo fracionamento do conhecimento e pela degradação do ambiente, marcados pelo logocentrismo da ciência moderna e pelo transbordamento da economização do mundo guiado pela racionalidade tecnológica e pelo livre mercado.

A crise ambiental e a crise do saber surgem como a acumulação de "externalidades” do desenvolvimento do conhecimento e do crescimento econômico. Surgem como todo um campo do real negado e do saber desconhecido pela modernidade, reclamando a “internalização” de uma “dimensão ambiental” através de um "método interdisciplinar”, capaz de reintegrar o conhecimento para apreender a realidade complexa.

A Bomba Populacional de Paul Ehrlich (1968), o Congresso de Nice sobre Interdisciplinaridade de 1968 (APOSTEL et al, 1975), a Teoria Geral de Sistemas de BERTALANFFY (1968), O Homem Unidimensional de Herbert Marcuse(1968), Da Gramatologia, de Derrida (1967), A Arqueologia do Saber, de Michel Foucault(1969), são indicadores da eclosão até finais dos anos 60 de uma nova consciência ecológica frente ao logocentrismo, a racionalidade tecnológica

\footnotetext{
* Artigo publicado em PHILIPPI JR., Arlindo (Org.). Interdisciplinaridade em ciências ambientais. São Paulo : Signus, 2000.

** Professor da Universidade Nacional Autônoma do México e Coordenador da Rede de Formação Ambiental para a América Latina e Caribe do PNUMA - Programa das Nações Unidas para o Meio Ambiente. E-mail: <enrique.leff@yahoo.com>.
} 
e a crise do crescimento econômico e populacional. Em princípios dos anos 70, Nicolás Georgescu Roegen (1971) publica A Lei da Entropia e o Processo Econômico e se difunde mundialmente o estudo do Club de Roma, Os Limites do Crescimento (MEADOWS et al, 1972), marcando os limites que a natureza impõe à racionalidade econômica.

Com esses antecedentes, a Conferência das Nações Unidas sobre o Meio Ambiente Humano, celebrada em Estocolmo em 1972, lança uma cruzada em favor do meio ambiente; ao mesmo tempo, porém, reconhece que a solução da problemática ambiental implica mudanças profundas na organização do conhecimento. Dessa forma, propõe-se o desenvolvimento de uma educação ambiental fundada em uma visão holística da realidade e nos métodos da interdisciplinaridade.

Assim, em 1975 se estabelece o Programa Internacional de Educação Ambiental (PIEA), patrocinado pela UNESCO e pelo Programa das Nações Unidas para o Meio Ambiente (PNUMA). Mais tarde, na Conferência Intergovernamental sobre Educação Ambiental, celebrada em Tbilisi em 1977, estabelecem-se as orientações gerais da educação ambiental, fundada em princípios da interdisciplinaridade como método para compreender e restabelecer as relações sociedade-natureza (UNESCO, 1980). O PIEA buscou incorporar uma "dimensão ambiental" nas diferentes disciplinas, assim como nos métodos de investigação e nos conteúdos do ensino formal e informal, em Nessa perspectiva, reconhece-se que os problemas ambientais são sistemas complexos, nos quais intervêm processos de diferentes racionalidades, ordens de materialidade e escalas espaçotemporais. A problemática ambiental é o campo privilegiado das inter-relações sociedade-natureza, razão pela qual seu conhecimento demanda uma abordagem holística e um método interdisciplinar que permitam a integração das ciências da natureza e da sociedade; das esferas do ideal e do material, da economia, da tecnologia e da cultura (UNESCO, 1986). ${ }^{1}$

Nessa reflexão epistemológica e metodológica sobre a complexidade e a interdisciplinaridade nas relações sociedade-natureza, tem predominado uma visão naturalista, biologista e ecologista (MORIN, 1973, WILSON, 1975); no campo da educação ambiental, a atenção tem se concentrado nos problemas de conservação dos recursos naturais, na preservação da biodiversidade e na solução dos problemas da contaminação do ambiente. Paulatinamente passou-se da noção de ambiente que considera essencialmente os aspectos biológicos e físicos, a uma concepção mais ampla, que dá lugar às questões econômicas e sócio-culturais, reconhecendo que, se os aspectos biológicos e físicos constituem a base natural do ambiente humano, as dimensões socio-culturais e econômicas definem as orientações conceituais, os instrumentos técnicos e os comportamentos práticos que permitem ao homem compreender e utilizar melhor os recursos da biosfera para a satisfação de suas necessidades (UNESCO,1980).

A partir desses princípios, na América Latina ocorreu um forte impulso para a reflexão e para a promoção da formação ambiental, através de uma série de seminários organizados pelo Centro Internacional de

\footnotetext{
${ }^{1}$ A educação relativa ao ambiente... tem como meta permitir ao ser humano compreender a natureza complexa do ambiente, tal como esta resulta da interação de seus aspectos biológicos, físicos, sociais, econômicos e culturais. Em consequência, deverá oferecer os meios para interpretar a interdependência desses diversos elementos no espaço e no tempo, para favorecer uma utilização mais sensata e prudente dos recursos do universo para a satisfação das necessidades da humanidade. (UNESCO/UNEP 1985)
} 
Formação em Ciências Ambientais (CIFCA) - programa conjunto do PNUMA com o governo da Espanha que funcionou desde 1976 até 1983 - e pela Rede de Formação Ambiental para América Latina e Caribe, do PNUMA, desde seu estabelecimento em 1981. Esses esforços levaram à organização do Primeiro Seminário sobre Universidade e Meio Ambiente, organizada pela Rede de Formação Ambiental e pelo PIEA em Bogotá, em 1985, que estabeleceu as bases para o desdobramento de diversos programas de investigação e estudo nas universidades da região, orientadas pelos princípios da "interdisciplinaridade ambiental” (PNUMA, 1985; PNUMA/ UNESCO, 1988).

Hoje pode-se identificar na região da América Latina e Caribe diversos programas "interdisciplinares" de investigação e formação ambiental (PNUMA, 1995), nos quais se desenvolvem estratégias acadêmicas e experiências muito diferentes. Reconhecendo os avanços feitos na investigação e na formação ambiental que demandam a interdisciplinaridade como fundamento teórico e guia pedagógico, é possível afirmar que são poucos os programas que trabalham a problemática epistemológica e metodológica da interdisciplinaridade para fundamentar seus programas de investigação e de estudo². Mesmo

\footnotetext{
2 Existem honrosas exceções e importantes contribuições, como as pesquisas realizadas no Instituto de Estudos Ambientais da Universidade Nacional de Colômbia; as pesquisas em torno do doutorado em Meio Ambiente e Desenvolvimento da Universidade Federal do Paraná (ZANONI; RAYNAUT, 1994, FLORIANI, 1998) e do Programa de Pós-Graduação em Ciência Ambiental da Universidade de São Paulo (JACOBI, 1999); as reflexões que fundamentam as pesquisas do Centro de Investigações Ambientais da Universidade Nacional de Mar del Plata e o mestrado em Gestão Ambiental do Desenvolvimento Urbano nessa Universidade, assim como nas Universidades de Comahue e Córdoba na Argentina (FERNÁNDES, 1999). Além disso, as contribuições à análise da interdisciplinaridade e à construção e aplicação de métodos interdisciplinares de investigação
}

que tenham sido abertos espaços de formação ambiental (ainda marginais) nas universidades, a interdisciplinaridade se incorpora, na maior parte das vezes, como um princípio que se satisfaz com a multiplicidade de temas ambientais introduzidos no currículo.

A reflexão em torno dos problemas do conhecimento que apresenta a questão ambiental foi orientado para a incorporação de um saber ambiental emergente nos paradigmas "normais" de conhecimento (das disciplinas científicas estabelecidas), buscando com isso estabelecer bases para uma gestão racional do ambiente (LEFF et al, 1986). Da concepção de uma educação ambiental fundada na articulação interdisciplinar das ciências naturais e sociais, se avançou para uma visão da complexidade ambiental aberta a diversas interpretações do ambiente e a um diálogo de saberes. Nessa visão se confluem a fundamentação epistemológica e a via hermenêutica na construção de uma racionalidade ambiental que é mobilizada por um saber ambiental que se inscreve em relações de poder pela apropriação social da natureza e da cultura (LEFF, 1986, 1994b, 2000).

A interdisciplinaridade implica assim um processo de inter-relação de processos, conhecimentos e práticas que transborda e transcende o campo da pesquisa e do ensino no que se refere estritamente às disciplinas científicas e a suas possíveis articulações. Dessa maneira, o termo interdisciplinaridade vem sendo usado como sinônimo e metáfora de toda interconexão e "colaboração" entre diversos campos do conhecimento e do saber dentro de projetos que envolvem tanto as diferentes disciplinas acadêmicas, como as práticas não científicas que incluem as instituições e atores sociais diversos. É

desenvolvidos na América Latina (FOLLARI,1982; GARCÍA, 1986, 1994; NOVO e LARA, 1997), que permeiam e dão suporte a muitos projetos de pesquisa e formação ambiental nas universidades da região. 
comum que diversos centros e organizações não-governamentais, dedicados não só à educação e à formação ambiental como também à assessoria e promoção de projetos de desenvolvimento (regional, social, comunitário), se autodenominem e se assumam como centros de estudos interdisciplinares (exemplo disso é o Foro Latino-Americano de Ciências Ambientais na Argentina, ou o Centro de Estudos Regionais Interdisciplinares no Paraguai).

Neste contexto, a noção de interdisciplinaridade se aplica tanto a uma prática multidisciplinar (colaboração de profissionais com diferentes formações disciplinares), assim como ao diálogo de saberes que funciona em suas práticas, e que não conduz diretamente à articulação de conhecimentos disciplinares, onde o disciplinar pode referir-se à conjugação de diversas visões, habilidades, conhecimentos e saberes dentro de práticas de educação, análise e gestão ambiental, que, de algum modo, implicam diversas "disciplinas"- formas e modalidades de trabalho - , mas que não se esgotam em uma relação entre disciplinas científicas, campo no qual originalmente se requer a interdisciplinaridade para enfrentar o fracionamento e a superespecialização do conhecimento.

Essas considerações colocam a necessidade de voltar a uma reflexão crítica sobre os marcos conceituais e as bases epistemológicas que podem impulsionar uma prática da interdisciplinaridade mais aprofundada e mais bem fundamentada em seus princípios teóricos e metodológicos, orientada ao manejo, gestão e apropriação dos recursos ambientais.

\section{A crise ambiental como problema do conhecimento: estratégias epistemológicas e apropriação de saberes}

Hoje se afirma que, graças à modernidade, à Revolução Científica e ao processo de globalização impulsionado pela revolução cibernética e informática, o homem entra em uma nova etapa civilizatória: a era do conhecimento. Isso é verdade, porque nunca antes ele havia construído e transformado o mundo com tanta intensidade sobre a base do conhecimento. Ao mesmo tempo em que o ser humano superexplora recursos e desgasta ecossistemas para convertê-los em valor de troca, "tecnologiza" a vida e coisifica o mundo. A ciência e a tecnologia se converteram na maior força produtiva e destrutiva da humanidade.

Mas essa civilização do conhecimento é, ao mesmo tempo, a sociedade do desconhecimento, da alienação generalizada, da deserotização do saber e o desencantamento do mundo (a sociedade dos poetas mortos; uma sociedades em propósito, sem imaginação, sem utopia, sem futuro). Nunca antes na História houve tantos seres humanos que desconhecessem tanto e estivessem tão excluídos dos processos e das decisões que determinam suas condições de existência; nunca antes houve tanta pobreza, tanta gente alienada de suas vidas, tantos saberes subjugados, tantos seres que perderam o controle, a condução e o sentido de sua existência; tantos homens e mulheres desempregados, desenraizados de seus territórios, desapropriados de suas culturas e de suas identidades. Nessa civilização supercientificada e "hipertecnologizada", tanto os que dominam como os que são dominados, se encontram alienados de seus mundos de vida, em um mundo no qual a incerteza, o risco e o descontrole aumentam proporcionalmente ao 
aumento dos efeitos de domínio da ciência sobre a natureza.

O pragmatismo político, que busca resolver as urgências da crise econômica, política e ecológica pela via de tornar eficientes os processos científicos, tecnológicos e econômicos, tem acarretado uma crescente desvalorização do conhecimento. Isso não só se reflete pelos poucos recursos destinados à educação, à ciência e à tecnologia na maior parte dos países da América Latina e Caribe; reflete-se também pela falta de políticas de pesquisa interdisciplinar para o desenvolvimento sustentável, pelo abandono do propósito de alcançar uma capacidade de auto-determinação científico-tecnológica, pelo esquecimento dos saberes e práticas tradicionais de uso sustentável dos recursos naturais.

Marx afirmava que os filósofos haviam se preocupado em entender o mundo e anunciou a hora de transformá-lo. No entanto, o projeto revolucionário socialista, que desmascarou a ideologia burguesa e o do socialismo utópico - que procurou construir um socialismo científico fundado em um materialismo dialético -, não chegou a questionar as formas históricas do conhecimento como raiz e causa de exploração da natureza e da submissão das culturas. O conhecimento científico continuou sendo a alavanca do progresso econômico, a pedra de toque para a construção de um socialismo - inclusive de rosto humano - que permitiria transcender o mundo da necessidade e abrir o reino da liberdade e bem-estar para todos. O socialismo científico não questionou o vínculo do ser ao conhecimento e sua dominação da natureza. Foram Nietzsche e Heidegger - e mais tarde os filósofos da Escola de Frankfurt - que traçaram o perfil de uma crítica radical das raízes do pensameno metafísico, da ciência positivista e da racionalidade tecnológica em sua vontade de universalidade, homoge- neidade e unidade do conhecimento, de objetivação e coisificação do ser, que geraram a atual globalização unidimensional, regida e valorizada pelo modelo econômico: a "sobreconomização” do mundo (LEFF 2000).

Heidegger formulou a crítica ao conceito de verdade como acordo, adequação, correspondência ou reflexo, que fertilizou o terreno da epistemologia desde a Antiguidade, abrindo a perspectiva hermenêutica e a via interpretativa da verdade. Certamente o cognitivismo colocou as vias de sentido pelas quais o mundo é construído através de cosmovisões e imaginários para chegar à compreensão do mundo como contrução social. A partir daí pode-se interrogar as formas nas quais o conhecimento e a teoria, a linguagem e a gramática - e não só a tecnologia - constroem o mundo e o real: não apenas como imagem do mundo, não só como efeito tecnológico, senão como construção de uma legalidade que, legitimada como ciência, gera uma norma de verdade, cujo exemplo mais totalitário e globalizador é a racionalidade econômica ${ }^{3}$.

A partir daí, abre-se uma reflexão crítica sobre os fundamentos e os sentidos do conhecimento; sobre suas fissuras e seus fracionamentos; sobre a possibilidade de reintegrar conhecimentos e saberes que, mais além do afã retotalizador das visões holísticas e os métodos sistêmicos, abra uma via de reapropriação do mundo pela via do saber. É nessa perspectiva que se inscreve, hoje em dia, a reflexão sobre uma prática interdisciplinar fundada em um saber ambiental (LEFF, 1986; 2000); a partir dessa perspectiva, possível recuperar/

\footnotetext{
${ }^{3}$ Heidegger mostra, com justiça, que a definição chamada 'tradicional' da verdade como 'acordo (correspondência, adequação) do conhecimento e da coisa' (que, de fato, é a inversão recente de uma tese teológica que expressa que o Intelecto divino é o nome da Verdade) pressupõe um sentido mais originário... que é o legítimo, o autêntico (só o ouro verdadeiro é ouro; quer dizer,o único que mede os valores). (BALIBAR, 1995)
} 
atualizar as argumentações expostas no início sobre os princípios epistemológicos para a articulação das ciências no campo ambiental (LEFF 1981, 1986).

A necessidade de uma estratégia epistemológica para a interdisciplinaridade ambiental adquire sentido para enfrentar as ideologias teóricas geradas por uma ecologia generalizada e um pragmatismo funcionalista, que não só desconhecem o processo histórico de diferenciação, de constituição e especificidade das ciências e os saberes, como também desconhecem as estratégias de poder no conhecimento que existem no terreno ambiental ${ }^{4}$. Essa estratégia conceitual em torno da constituição do saber ambiental combate os principais efeitos ideológicos do reducionismo ecologista e do funcionalismo sistêmico, a saber:

a) Pensar o homem como indivíduo e as formações sociais como populações biológicas inseridas no processo evolutivo da natureza, o que leva a explicar a conduta humana e a práxis social através de suas determinações genéticas ou sua adaptação funcional ao meio (WILSON 1975). As teorias sócio-biológicas e ecologistas desconhecem a especificidade das relações sociais de produção, as regras de organização cultural e as formas de poder político nas quais se inscrevem as estratégias do conhecimento e as formas de uso dos recursos naturais.

b) Considerar a Ecologia como a disciplina por excelência das interrelações, a fim de convertê-la em uma "teoria geral de sistemas", em uma "ciência das ciências"

\footnotetext{
${ }^{4}$ Nesse sentido, e seguindo Foucault, a emergência do saber ambiental estaria manifestando a surpreendente eficácia da crítica descontínua, particular e local frente ao efeito inibidor das teorias totalitárias e dos paradigmas globalizadores. Estar-se-ía, assim, testemunhando a insurreição dos saberes subjugados dos conteúdos históricos que foram enterrados e mascarados em uma coerência funcionalista ou em uma sistematização formal.. (FOUCAULT, 1980).
}

capaz de integrar as diferentes ordens do real - e os diferentes processos materiais e simbólicos - como subsistemas de um ecossistema global. Assim, a ecologia generalizada (MORIN 1980) promete uma reconstrução da realidade como um todo pela integração dos diversos ramos do saber em um processo interdisciplinar, dificultando a reconstrução do real histórico a partir da especificidade e da articulação de processos de ordem natural e social: econômicos, ecológicos, tecnológicos e culturais. De forma similar, Bookchin (1990) busca estabelecer uma ecologia social, fundada na filosofia de um "naturalismo dialético", capaz de entender a evolução da sociedade frente à emergência de uma consciência ecológica ordenadora de uma sociedade ecocomunitária (LEFF).

c) Fundar a interdisciplinaridade na Teoria Geral de Sistemas (BERTALANFFY, 1968) que desconhece a constituição ontológica do real no momento de estabelecer as inter-relações possíveis entre diferentes ordens de materialidade através dos isomorfismos e analogias estruturais que se configuram desde a análise formal dos processos estudados, excluindo o valor da diferença e o potencial do heterogêneo ${ }^{5}$, ignorando o sentido da identidade que se configura no saber.

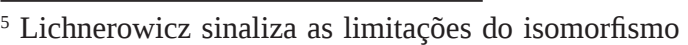
na apreensão de objetos ontológicos diferentes: O matemático trabalha sempre com um dicionário quase perfeito e frequentemente identifica sem escrúpulos objetos de natureza diferente quando um ... isomorfismo lhe assegura que só estaria dizendo a mesma coisa duas vezes em duas línguas diferentes. O isomorfismo toma o lugar da identidade. O Ser se encontra posto entre parênteses, e é precisamente esta característica não-ontológica que dá às matemáticas seu poder, sua fidelidade e sua polivalência. Podemos tecer uma matemática de uma textura arbitrariamente fechada, mas a onda ontológica se escorreria necessariamente nelas. (LICHNEROWICZ, 1975).
} 
d) Orientar a produção de conhecimentos por um critério de eficácia e eficiência na integração de um sistema científicotecnológico a um sistema social dado, como um instrumento de controle e de adaptação funcional da natureza e da sociedade através da ciência, submetendo a esse propósito o potencial crítico, criativo e transformador do conhecimento. Busca-se desta forma o acoplamento de um saber holístico e sistêmico sem fissuras, a um todo social sem divisões.

e) Confundir as condições teóricas para a produção de conhecimentos interdisciplinares sobre os processos materiais que convergem em sistemas socioambientais complexos (interdisciplinaridade teórica), com a aplicação e a integração de um conjunto de saberes técnicos e práticos no processo de planejamento e gestão ambiental (interdisciplinaridade técnica) (LEFF 1981; 1986).

f) Reduzir o estudo das determinações estruturais e dos sistemas de organização de diferentes ordens de materialidade do real, a uma energética, a um cálculo dos fluxos de matéria e energia, que, se bem que resulta útil para o fim prático de avaliar o potencial produtivo e a sustentabilidade dos ecossistemas através de diferentes práticas culturais e econômicas de uso e apropriação da natureza (RAPPAPORT, 1971), não constitui o princípio último de conhecimento sobre a organização dos processos ecológicos, econômicos e simbólicos; das relações entre a natureza, a técnica e a cultura.

Contra os efeitos reducionistas - de formalistas, empiristas, ecologistas - dessas abordagens metodológicas a uma pretendida interdisciplinaridade ambiental, se constroem os princípios epistemológicos que dão sua especificidade às ciências e às formas de articulação da ordem física, biológica, histórica e simbólica. Os efeitos combinados desses processos convergem para uma problemáti- ca ambiental, mas sua "materialidade” não é visível na realidade empírica dos fluxos de energia do ecossistema, nem na utilidade de seus recursos como objetos de trabalho, nem em sua manifestação como valores de mercado. A materialidade desses processos está definida pela especificidade do real do qual dão conta os conceitos teóricos de diferentes ciências; de um real presente e produtivo (o potencial ecológico, a organização cultural), invisíveis na realidade perceptível do sujeito psicológico e oculto ao olhar dos paradigmas econômicos e tecnológicos dominantes.

Essa afirmação embute de maneira implícita uma definição do conhecimento científico dentro do campo do saber ambiental. As ciências são corpos teóricos que integram conceitos, métodos de experimentação e formas de validação do conhecimento, que permitem apreender cognoscitivamente a estruturação e a organização de processos materiais e simbólicos, para entender as leis e as regularidades de seus fenômenos, para estabelecer os parâmetros e o campo dos possíveis eventos nos processos de reprodução e transformação do real que constitui seus objetos científicos específicos: processos de produção, de reprodução e de transformação social; processos de adaptação-transformação-mutação-biológica; processos de simbolização cultural e de significação ideológica.

Todos esses são processos gerais, mas não redutíveis a uma ordem globalizadora e a um padrão uniforme de medida. Tais processos - de onde emerge a produtividade do real -, determinam, em seus efeitos práticos, a articulação dos processos econômicos com os processos de conservação, desestruturação, regeneração dos ecossistemas, com a valorização cultural dos recursos, com os processos ideológicos e discursivos nos quais se inscrevem as inovações do conhecimento científico, dos meios tecnológicos e dos saberes locais, com os processos políti- 
cos que abrem as possibilidades do acesso e apropriação social da natureza. São os efeitos desses processos materiais e simbólicos que se articulam e se tornam visíveis nos padrões tecnológicos e nas formas particulares de organização produtiva; nos circuitos da produção, distribuição e consumo; na organização institucional do poder; na eficácia dos métodos de produção, difusão e aplicação do conhecimento; nas atitudes frente à inovação tecnológica e à mudança social; na retórica das práticas discursivas sobre a conservação ecológica e o desenvolvimento sustentável.

A materialidade dos citados processos se forja entre o real do objeto do conhecimento de suas ciências e a realidade onde seus efeitos são perceptíveis. Os conceitos teóricos apreendem as causas determinantes e os princípios atuantes dessa organização do real, de onde é possível explicar a dinâmica destes processos, sua potencialidade e seus efeitos concretos sobre a realidade empírica. Essa produção de conhecimentos não se constitui a partir da simples indução da realidade sensível, pela formalização dos dados "puros" da realidade e dos enunciados sobre os fenômenos observáveis, ou pela "sistematicidade” das possíveis relações lógicas e "matematizáveis" em uma teoria geral de sistemas. Nesse sentido, a estratégia epistemológica proposta para compreender as possíveis articulações das ciências no campo da interdisciplinaridade ambiental, acaba sendo oposta ao positivismo lógico e a todo idealismo empirista e subjetivista.

Os princípios anteriores se constroem como "postos de vigilância epistemológica" frente às tendências idealistas à dissolução das diferenças nas ordens ontológicas do real, dos objetos das ciências e das racionalidades que organizam os saberes em um campo unitário do conhecimento; em oposição à redução da organização específica dos diferentes níveis do real em princípios gerais ou supostamente fundamentais de seu funcionamento estrutural - e não só de sua gênese histórica ou evolutiva.

O propósito de unificação das ciências no positivismo lógico e a busca de suas homologias estruturais na Teoria Geral de Sistemas, foi conformando uma prática interdisciplinar que não foge a essa racionalidade científica que tem "externalizado" o ambiente e que desconhece o saber ambiental. O objetivo unificador e reducionista do logocentrismo da ciência moderna surge do desejo de encontrar um único princípio organizador da matéria, como se experimentara uma singular repugnância ao pensar a diferença, a descrever as separações e suas dispersões, a dissociar a forma reafirmante do idêntico. (FOUCAULT, 1969). Esses sistemas desconhecem a especificidade conceitual de cada ciência, de onde é possível pensar sua integração com outros campos do conhecimento, sua articulação com outros processos materiais e sua hibridação com outros saberes.

As ciências não vivem num vazio ideológico e semântico. Tanto por sua constituição a partir das ideologias teóricas e as cosmovisões do mundo no terreno conflitivo das práticas sociais dos homens, como pelas transformações tecnológicas que se abrem a partir das condições econômicas de aplicação do conhecimento, as ciências estão inseridas em processos discursivos onde se debatem num processo contraditório de conhecimento/desconhecimento que mobiliza o "lugar da verdade" (BALIBAR, 1995), de onde derivam sua capacidade "cognoscitiva" e seu potencial transformador da realidade. A articulação desses processos de conhecimento com os processos institucionais, econômicos e políticos que condicionam o potencial tecnológico e a legitimidade ideológica de suas aplicações, está regida pela confrontação de interesses opostos de classes, grupos sociais, 
culturas e nações pela apropriação diferenciada e pelas transformações alternativas da natureza.

A produção científica se inscreve nessas condições ideológicas, não só porque o cientista, como sujeito da ciência, é, desde sempre, um sujeito ideológico, mas também porque suas práticas de produção de conhecimento estão estreitamente vinculadas às ideologias teóricas e modeladas no tecido do saber de onde emergem as ciências, e onde se debatem permanentemente em um processo interminável de emancipação, de produção e especificação de seus conhecimentos.

As formações ideológicas nas quais se desenvolvem os métodos da interdisciplinaridade ambiental tendem a "naturalizar" os processos políticos de dominação e a ocultar os processos de reapropriação da natureza que estabelecem as estratégias dominantes da globalização econômica. Dessa maneira, pretende-se explicar e resolver a problemática ambiental através de uma visão funcional da sociedade, inserida como um subsistema dentro do ecossistema global do planeta, ocultando os interesses em jogo no conflito pela apropriação da natureza na legalidade dos direitos individuais e na unidade do saber sobre uma realidade uniforme.

Nesse sentido, o saber ambiental abre uma perspectiva de análise da produção e de aplicação de conhecimentos como um processo que compreende condições epistemológicas para as possíveis articulações entre ciências e os processos de internalização do saber ambiental emergente nos árduos núcleos da racionalidade científica, e a hibridização das ciências com o campo dos saberes "tradicionais", populares e locais. A produção "interdisciplinar" de conhecimentos se insere, dessa maneira, no marco das lutas por certa autonomia cultural, pela autogestão dos recursos das comunidades, pela propriedade das terras de uma população; pela produção e pela aplicação de certos conhecimentos que permitam uma apropriação coletiva dos recursos naturais, uma produção sustentável e uma divisão mais equitativa da riqueza, para satisfazer as necessidades básicas das comunidades e para melhorar sua qualidade de vida.

A problemática ambiental induz, assim, um processo mais complexo do conhecimento e do saber para apreender os processos materiais que configuram o campo das relações sociedade-natureza. Daí surgem obstáculos epistemológicos (BACHELARD, 1938) e motivações para a produção de conhecimentos pelo efeito de interesses sociais opostos, abrindo possibilidades alternativas para a reorganização produtiva da sociedade e o aproveitamento sustentável dos recursos naturais. As distintas percepções da problemática ambiental - as causas da crise de recursos, as desigualdades do desenvolvimento econômico, a distribuição social dos custos ecológicos, a nova racionalidade produtiva fundada no potencial ambiental de cada nação, região, território, população, comunidade - geram demandas diferenciadas de conhecimentos teóricos e práticos. Dessa forma, a "crise ecológica" mobiliza um amplo processo de produção, apropriação e utilização de conceitos "ambientais" que se reflete nas estratégias para o aproveitamento sustentável dos recursos.

Para poder abordar a questão da interdisciplinaridade e orientar tanto estratégias de investigação e de formação como políticas ambientais e de desenvolvimento sustentável, deve-se reconhecer os efeitos das políticas econômicas atuais sobre a dinâmica dos ecossistemas e sobre as condições de vida das comunidades. É necessário avaliar as condições econômicas, políticas, institucionais e tecnológicas que determinam a conservação e recuperação dos recursos de uma 
região, os estilos de ocupação do território, as formas de apropriação e usufruto dos recursos naturais e da partilha de suas riquezas, assim como o grau e as formas de participação comunitária na gestão social de seus recursos e de suas atividades produtivas.

É necessário também estudar os efeitos da problemática ambiental sobre as transformações metodológicas, as transferências conceituais e a circulação terminológica entre as diferentes disciplinas que fazem parte da explicação e diagnóstico das mudanças socioambientais, assim como a forma como esses paradigmas produzem e assimilam um conceito de meio ou de ambiente e as diferentes interpretações e discursos sobre a sustentabilidade ambiental e o crescimento sustentável. Do estudo de tais mudanças epistêmicas surge a possibilidade de gerar estratégias de conhecimento para orientar uma transformação produtiva fundamentada nos princípios de uma racionalidade ambiental para o manejo sustentável dos recursos.

O saber ambiental está transitando, assim, do desafio da interdisciplinaridade para a abertura de um diálogo de saberes. A interdisciplinaridade que coloca a complexidade ambiental não é aquela de um simples somatório e combinação dos paradigmas de conhecimento que construíram os compartimentos disciplinares das universidades. A interdisciplinaridade ambiental estabelece a transformação dos paradigmas estabelecidos do conhecimento para internalizar um saber ambiental. $\mathrm{Na}$ verdade, esse saber ambiental ficou excluído num processo de extermínio dos saberes "nãocientíficos" (saberes errantes, ciganos, nômades), no campo de concentração das externalidades do sistema econômicopolítico e científico-tecnológico dominante. Esse saber é mais do que uma "dimensão" internalizável através de uma visão holística e uma vontade sistêmica. Não se trata de vincular os compartimentos estanques do conhecimento a partir de suas homologias estruturais, de sistemas formais esvaziados dos seus referentes ontológicos e dos seus sentidos existenciais, de onde derive a essência ontológica dos processos, o ser das coisas e a identidade dos sujeitos sociais.

Para lá da interdisciplinaridade entendida como a transformação de seus núcleos fortes de racionalidade pela internalização do saber ambiental (de suas externalidades) - para lá da articulação de processos ontológicos -, a complexidade ambiental se abre para um diálogo de saberes que acarreta uma abertura à inter-relação, ao confronto e ao intercâmbio de interesses, em uma relação diametral que vai da solidariedade e complementariedade entre disciplinas, ao antagonismo de saberes; onde se inter-relacionam processos significativos, mais que posições científicas, interesses disciplinares e verdades objetivas.

Isso significa que os conflitos ambientais não serão resolvidos pelo poder científico da economia ou da ecologia, senão através de sentidos existenciais, de valores culturais e de estilos de desenvolvimento diferenciados, nos quais a exploração, a conservação ou o uso sustentável dos recursos dependem dos significados sociais atribuídos à natureza. O ambiente não é só um objeto complexo a ser controlado por meios mais eficazes, senão também um co-relato de processos significativos que mobilizam os agentes sociais para tomar posição frente à posse e ao usufruto da natureza. O conflito ambiental está marcado por interesses pela apropriação da natureza como fonte de riqueza e suporte de práticas produtivas. Nesses processos, os conhecimentos e os saberes jogam um papel instrumental ao potenciar a apropriação econômica da natureza; mas também jogam como saberes que forjam sentidos e que 
mobilizam a ação com valores não mercantis e para fins não materiais nem utilitários.

A ruptura epistemológica em diferentes paradigmas do conhecimento, que gera a emergência do saber ambiental e sua possível "internalização", provém do encontro entre os núcleos de racionalidade das ciências e o campo do saber ambiental, entendido como um "espaço de externalidade". Tal encontro é a confrontação com o real posto à margem, confinado e excluído, externalizado do núcleo conceitual do objeto de conhecimento (as condições ecológicas da reprodução do capital e as condições termodinâmicas do processo econômico). Mas, por ele mesmo, não se trata da internalização mecânica de uma "dimensão" do conhecimento, de um conjunto de princípios, preceitos, conhecimentos, métodos e técnicas. Refere-se mais ao retorno dos impensáveis, do que só será pensável fazendo atuar a reflexão sobre o já pensado, voltanto sobre os próprios fundamentos de uma ciência, sobre seus conceitos e pressupostos básicos (LEFF, 2000) ${ }^{6}$.

O ambiente não é o conceito que designa a ruptura de uma ciência ou da articulação das ciências existentes. O ambiente é o campo de externalidade das ciências; é o conceito da demarcação frente à "cientificidade” própria que instaura a modernidade, o logocentrismo que fundamenta as ciências em torno de núcleos conceituais que externalizam e ignoram o ambiente que condiciona os processos dos quais deve dar conta uma ciência; é a disjunção do pensamento unidimensional e do conhecimento disciplinar

\footnotetext{
${ }^{6}$ A "ambientalização" das ciências implica uma reestruturação epistemológica que, como coloca F. Regnault, é o ponto de retorno aos impensados desta ciência que, ao mesmo tempo, é um novo ponto sem retorno para esta ciência. (cit. em BALIBAR4 1995). Trata-se de um retorno dos impensados... no sentido de uma produção de conceitos, que permite formular completamente a teoria existente e, portanto, exibir seus limites.” (BALIBAR4 1995)
}

que se abre para o saber da complexidade ambiental.

A interdisciplinaridade é uma chamada para a complexidade, a restabelecer as interdependências e inter-relações entre processos de diferentes ordens de materialidade e racionalidade, a internalizar as externalidades (condicionamentos, determinações) dos processos excluídos dos núcleos de racionalidade que organizam os objetos de conhecimento das ciências (de certos processos ônticos e objetivos). Nesse sentido, a interdisciplinaridade é uma busca de "retotalização" do conhecimento, de "completude" não alcançada por um projeto de cientificidade que, na busca de unidade do conhecimento, da objetividade e do controle da natureza, terminou fraturando o corpo do saber e submetendo a natureza a seus designios dominantes; exterminando a complexidade e subjugando os saberes "não científicos", saberes não ajustáveis às normas paradigmáticas da ciência moderna.

Desde uma visão hermenêutica sobre a constituição do conhecimento científico, pode-se compreender o desconhecimento em que se fundamenta. Assim, a afirmação de que a globalização - regida com base nas leis clarividentes do mercado - é a razão máxima de governabilidade do mundo, não pode assegurar a certeza do conhecimento no qual se fundamenta. $\mathrm{O}$ que faz é expulsar do campo da percepção todo possível questionamento das causas profundas da crise ambiental. Dessa maneira, tal excesso de conhecimento segue descarregando-se como resíduos tóxicos e perigosos na natureza; os investimentos de capital se transformam em emissões térmicas que seguem sendo depositadas na natureza, transformando seus rendimentos em desastres naturais que castigam os ecossistemas e os povos do mundo (e com maior severidade os países tropicais do Terceiro Mundo e os povos da América Latina e Caribe). 
O processo de globalização econômica organiza rituais para venerar o deus-mercado, para pedir-lhe maiores colheitas de crescimento sustentável, sem considerar que é esse crescimento econômico, regido pelas leis do mercado e por uma racionalidade do lucro de curto prazo (leis humanas sujeitas ao poder entre humanos), que produz os ritmos crescentes de extração e transformação de recursos naturais, de matéria e energia sujeita às leis da entropia. É isso que se manifesta no aquecimento global do planeta, ocasionando os ritmos atípicos e extremos de altas e baixas temperaturas, os furacões e ciclones, os incêndios florestais dos últimos anos que tornaram inoperantes as práticas tradicionais de uso do solo e do fogo (que estão convertendo a desgraça humana e o desastre ambiental em oportunidades de negócio para a recuperação ecológica, tão demandada nos programas globais de desenvolvimento "limpo").

Para salvar os problemas que colocam a interdisciplinaridade como processo de recomposição do saber fracionado, se postula a transdisciplina como sua solução final: um conhecimento holístico e integrador, sem falhas nem vazios; um conhecimento reunificador que transcende o propósito de estabelecer pontes interdisciplinares entre ilhotas científicas isoladas. No entanto, a transdisciplinaridade não é a constituição de uma super-disciplina (ecologia, termodinâmica) que transbordaria o campo das possíveis conexões entre disciplinas para estabelecer um paradigma onicompreensivo. A transdisciplinar não poderá constituir-se em uma meta-disciplina, senão em um processo de reconstrução do saber que transcenda a divisão e a configuração disciplinar do conhecimento em compartimentos estanques. A trans-disciplina é o processo mobilizador de um conhecimento apressado, ao qual se fecharam as vias da complexidade; é o encontro do conhecimento iso- lado com sua externalidade, com sua "alteridade", que abre as comportas do saber para irrigar novos territórios do ser; para que, em sua eterna recorrência, os conhecimentos se reencontrem com os saberes subjugados (naufragados) em novos horizontes de racionalidade.

A transdisciplinaridade é o questionamento do logocentrismo e da configuração paradigmática do conhecimento, do qual erradicou da ciência normal todo saber não científico como externo e estranho, como patológico, como "não conhecimento"; é a transgressão da disciplinaridade, do saber codificado para apreeender, "coisificar”, objetivar o real. A transdisciplina está no saber ambiental, como essa falta de conhecimento que anima a produção de novos conhecimentos; está na hibridização entre ciências, tecnologias e saberes; está no diálogo inter-cultural; é o saber que sabe que não pode saber tudo, que sabe que está movido por seu não-saber, pelo desejo de saber. A transdisciplinar leva, assim, à desconstrução do conhecimento disciplinar e abre as vias para uma hibridização e diálogo de saberes no campo da complexidade ambiental.

\section{Pensamento da complexidade, métodos interdisciplinares e diálogo de saberes}

Havendo sobrevoado a problemática da interdisciplinaridade, será possível agora uma maior aproximação no discernimento de suas estratégias epistemológico-metodológicas frente à complexidade ambiental.

A interdisciplinaridade tem sido definida como uma estratégia que busca a união de diferentes disciplinas para tratar um problema comum. Nesse caso, pode-se entender como um procedimento metodológico 
relacionado com o processo de "finalização das ciências", que, como resultado de ter alcançado um estado de "maturidade", deveria levá-las a redirecionar seu potencial aplicativo para a demanda social de conhecimentos (BÖHME et al, 1976, PRIGOGINE e STENGERS, 1979, JOLLIVET, 1992), internalizando uma exigência de "reintegração" e "retotalização". É neste sentido que diversas disciplinas podem repartir tarefas de pesquisa sem se afastar de seus conceitos e métodos, para contribuir em um projeto ou em uma problemática comum. Esses processos, que correspondem ao que se denomina uma interdisciplinaridade técnica, integram uma série de ciências e tecnologias aplicadas como uma divisão do trabalho intelectual, científico e técnico, tanto nos processos de produção, como em um conjunto de projetos sociais.

No entanto, o problema da interdisciplinaridade no conhecimento teórico continua sendo um problema manifesto e não resolvido. A crítica pós-moderna ao logocentrismo da ciência implica um problema de desconstrução e reconstrução do modelo dominante de cientificidade paradigmática como pré-requisito para poder traduzir os princípios da complexidade ambiental em políticas científicas e educativas explícitas em campos nos quais seguem predominando os esquemas institucionais da universidade napoleônica e da ciência moderna.

A formação ambiental - a construção do saber, dos métodos e dos projetos de pesquisa e de formação interdisciplinares - está sendo impulsionada por indivíduos (alguns dos quais trabalham em equipes de pesquisa) vinculados às universidades e aos centros nacionais de pesquisa científica, mas cujo interesse e paixão para transgredir os paradigmas disciplinares e para ultrapassar as fronteiras do conhecimento, não responde a uma política científica ou uma política universitária. Aqui se manifesta um discurso proto-interdisciplinar sobre a complexidade emergente; e esse discurso é bastante citado em um número crescente de publicações, livros e teses. As menções a Apostel (1975), a morin (1977, 1980, 1986, 1993), a PRIGOGINE (1979, 1984, 1997), a GARCÍA (1986, 1994), a FUNTOWICZ e RAVETZ (1993, 1994) poderão ser aumentadas. Mas isto não implica que se traduza em projetos de pesquisa e ensino que incorporem o propósito e levem a um resultado de interdisciplinaridade. Pois o propósito da interdisciplinaridade não conseguiu estabelecer um campo virtual entre os centros duros dos conhecimentos disciplinares constituídos em paradigmas, dentro dos quais se "faz ciência" e se faz uma carreira dentro das ciências. Tampouco se resolve em um curriculum ampliado no qual se quer fazer caber todos os nomes das ciências, de seus antecedentes e descendentes, de suas ciências básicas e suas ramificações especializadas.

A interdisciplinaridade ambiental implica a reconstrução dos objetos de conhecimento pela internalização dos campos ônticos desconhecidos e desalojados, dos saberes subjugados e postos à margem, mas que intervêm na determinação dos processos que estuda uma ciência. Em consequência, não é possível - ou não deveria ser possível - ensinar e praticar uma economia como disciplina que pretende explicar os processos de produção, se essa disciplina não introduz dentro da racionalidade econômica suas condições de sustentabilidade. E isso não se consegue com complexos diagramas de fluxos, retroalimentações de processos e interconexões entre "coisas" (as relações entre economia e ecologia, entre natureza e sociedade, entre população, tecnologia e recursos). A fundação do conhecimento interdisciplinar em geral - e especialmente no campo ambiental-, 
implica um rompimento epistemológico que funda uma nova ciência ou um novo campo do conhecimento.

O ambiente é um objeto complexo, onde se configuram entes híbridos, feitos de natureza, tecnologia e texto (HARAWAY, 1991, 1997; ESCOBAR, 1999, LEFF, 2000); que implica múltiplos processos materiais e simbólicos, diversas ordens ontológicas, formas de organização e racionalidades de caráter "não linear", de diferentes escalas e níveis (do local ao global) que, em sua conjugação, geram sinergias e novidades; o ambiente é um real solidário da complexidade, da diversidade, da "generatividade" e da criatividade. Mas, ao mesmo tempo, o ambiente é um pensamento complexo e um saber, que interage com o ambiente como "real complexo". Por ele, a complexidade ambiental emergente implica o encontro do real em vias de complexão com uma "complexidade reflexiva", com um pensamento que não é um "desenvolvimento" da "generatividade" ecológica, senão de processos de ressignificação do real, geradores de novas identidades em torno do saber (FUNTOWICZ, RAVETZ, 1994; LEFF, 1998; FUNTOWICZ e DE MARCHI, 2000; LEFF, 2000).

A complexidade ambiental reclama a participação de especialistas que trazem pontos de vista diferentes e complementares sobre um problema e uma realidade - a visão e a sensibilidade do ecólogo, do edafólogo, do geógrafo, do agrônomo, do geomorfólogo em relação ao "ambiente físico"; do economista, do sociólogo, do antropólogo e do historiador em relação ao "ambiente social”. No entanto, a interdisciplinaridade não só implica a integração dessas disciplinas genéricas; dentro de cada campo temático se desenvolvem "escolas de pensamento", com diferentes princípios teóricos, metodológicos e ideológicos, com posições diferenciadas que criam obstáculos ou favorecem o diálogo interdisciplinar pelas simpatias e antagonismos entre os portadores desses interesses disciplinares.

Pelo anterior, o saber ambiental, que demanda a complexidade ambiental, não se completa com a análise sistêmica das interrelações entre processos e níveis de organização, com a imbricação de suas múltiplas causalidades, sinergias e retroalimentações; pela combinação de todos esses conhecimentos e especialidades sobre os diferentes processos que integram o ambiente, que buscam retotalizá-lo com um conhecimento holístico gerado por um método interdisciplinar. Não se trata simplesmente de unir o que tem sido desunido pelo desenvolvimento das ciências, como postulam tantas abordagens interdisciplinares dessa problemática ${ }^{7}$. O saber ambiental não nega nem minimiza a importância das abordagens interdisciplinares para pensar e diagnosticar problemas ambientais complexos. Mas afirma que as causas profundas da crise ambiental - e suas manifestações nas diferentes "problemáticas ambientais" - remetem a um questionamento da racionalidade que as gera e à construção de uma nova racionalidade.

A construção de uma racionalidade ambiental demanda também a interdisciplinaridade, mas não só como um método integrador do existente, senão como uma perspectiva transformadora dos paradigmas atuais do conhecimento, da abertura à hibridização das ciências, das tecnologias e dos saberes populares. Nesse sentido, a racionalidade ambiental estabelece bases materiais e princípios conceituais para a construção de

\footnotetext{
Os componentes do ambiente, inicialmente dissociados numa abordagem de pensamento que conduziu à instauração do recorte disciplinar, devem ser de novo considerados hoje em seu conjunto, isto é, em função das múltiplas interações que os une. (ZANONI e RAYNAUT, 1994).
} 
uma nova economia fundada no potencial ambiental que produz a sinergia dos processos ecológicos, tecnológicos e culturais (LEFF34,39). A interdisciplinaridade aparece, assim, como processo produtor de novos conhecimentos. Esse é o significado que atribui Canguilhem (1977) quando entende a interdisciplinaridade como o processo que, através da intervenção de diversas disciplinas, funda ou refunda um objeto de conhecimento.

A interdisciplinaridade não é só uma prática teórico-metodológica, senão um conjunto de práticas sociais que intervêm na construção do ambiente como um real complexo. A interdisciplinaridade ambiental tem sido definida como o campo de relações entre natureza e sociedade, entre ciências naturais e ciências sociais (JOLLIVET, 1992). No entanto, o campo da complexidade ambiental não pode circunscrever-se ao das relações entre ciências. Se a questão ambiental demanda uma ressignificação do mundo e a reapropriação da natureza, a partir de um questionamento das formas de conhecimento e apropriação que produz a ciência moderna, ela significa uma revisão de suas formas de conhecimento e sua abertura para outras formas "não científicas" de compreensão do mundo, das relações do homem com a natureza. Quer dizer, não se trata somente da integração naturezasociedade por meio da inter-relação das ciências, senão da abertura para um diálogo de saberes, para a hibridização entre ciências, tecnologias e saberes, para a produção de novos paradigmas de apreensão do real e comunicação entre saberes, do encontro entre a epistemologia e a hermenêutica (VATTIMO,1992, CARVALHO, 2000, LEFF, 2000).

A interdisciplinaridade extende dessa maneira seu campo de intervenção "entre disciplinas científicas" para abarcar todo contato, intercâmbio, interrelação e articulação entre paradigmas, disciplinas, saberes e práticas. No entanto, para efeitos de compreensão e praticabilidade desses processos, é necessário diferenciá-los, pois cada um deles envolve diferentes estratégias de produção teórica, de abordagem dos problemas complexos, de investigação participativa e de construção coletiva de conhecimentos através do intercâmbio de saberes, assim como da hibridização de sabedorias e conhecimentos, cosmovisões e paradigmas científicos.

Nesse sentido, os conflitos ambientais que estão na raíz da problemática ambiental, e que implicam visões e interesses diferenciados, nos quais se inscrevem diferentes formas de saber e estratégias de poder no saber, não poderão anular-se, segurar-se e reintegrar-se dentro do campo próprio das ciências; por mais que estas contribuam para a clarificação e solução destes problemas, sua compreensão demanda uma abertura do cerco das ciência para um diálogo de saberes (LEFF, 1998) ${ }^{8}$.

\footnotetext{
${ }^{8}$ Nesse sentido, pode-se concordar em que deve-se evitar cair na ilusão de que 'mais ciências humanas' colocadas a serviço de um procedimento holístico para a análise dos fenômenos do ambiente e o desenvolvimento, seriam suscetíveis de dar aos atores uma abordagem unificada dos fatos - que se tornaria o fundamento científico de um consenso ou o instrumento da manipulação do real. Não se trata de atribuir ao social um cientismo ampliado para substituir ao que vem atuando, até o presente, sobre bases exclusivamente técnicas. Deve-se estar prevenido contra a tentação ‘totalitária’ que buscaria no enfoque holístico suas justificativas científicas. De qualquer maneira, a tentativa de assim proceder estaria destinada ao fracasso, uma vez que os conflitos de identidade, os confrontos de valores, as contradições de interesses formam a própria matéria, da qual se alimentam os processos sociais. (ZANONI e RAYNAUT, 1994). É nesse contexto que Funtowics e Marchi(1999) colocam os princípios éticos e pragmáticos de uma "ciência pós-normal” como um campo de conhecimento para apreender a complexidade reflexiva como o espaço onde o que está em
} 
Dessa maneira, haverá que distinguir os processos interdisciplinares da hibridização de conhecimentos e o diálogo de saberes, restringindo o conceito de interdisciplinaridade ao tratamento do trabalho no que concerne às relações entre disciplinas científicas constituídas dentro de paradigmas científicos, em sentido kuhniano (KUHN, 1962). Quer dizer, se bem que a interdisciplinaridade como mot d'ordre e método para ver e promover processos de integração e colaboração entre campos heterogêneos de conhecimento produz a estratégias heterodoxas de investigação, o sentido da interdisciplinaridade deveria limitar-se a denotar os procedimentos e objetivos intercientíficos da "ciência normal", que se remete a suas possibilidades de inter-relacionar processos e de articular conhecimentos a partir de seus métodos de investigação e suas óticas disciplinares dentro de seus próprios paradigmas científicos. A interdisciplinaridade terá que permitir desembaraçar e compreender os processos que implica um diálogo de saberes, assim como as hibridizações entre ciência, tecnologia e saberes que se manifestam no campo do conhecimento para a apropriação e transformação da natureza.

\section{Interdisciplinaridade e articulação de ciências no campo ambiental}

A problemática ambiental gerou na América Latina uma reflexão sobre a articulação das ciências para a gestão ambiental, abrindo o campo de uma

jogo são valores e interesses que transbordam a capacidade de mediação e compreensão das ciências. É nesse campo dos saberes situados e localizados, nos quais as comunidades, através de suas práticas, geram formas diferenciadas e específicas de relação e conhecimento universal, sem perder, no processo, sua autonomia e seu sentido. (ESCOBAR, 1997) interdisciplinaridade teórica. Tal proposta epistemológica estabelecia a reconstituição de objetos de conhecimento para internalizar o saber ambiental complexo, tudo mais além da vinculação entre duas ou mais disciplinas confluentes em uma problemática ambiental (LEFF et al, 1986).

A articulação da produção teórica orientada para os propósitos de alcançar a sustentabilidade do processo de desenvolvimento através das práticas sociais de produção e transformação da natureza -, transcende os alcances de um princípio metodológico para a reintegração dos conhecimentos existentes. A luta social pela reapropriação da natureza e do conhecimento está incidindo na produção teórica, assim como na inovação tecnológica com suas aplicações sociais e produtivas para a exploração e o aproveitamento sustentável da natureza.

A luta política pelo conhecimento é um debate para dissolver a representação imaginária da ciência como um processo neutro no qual o conhecimento se desenvolve como resultado de uma lógica interna conduzida pela ação metodológica de sujeitos autoconscientes frente a uma realidade objetiva. Nessa visão positivista, as esferas de materialidade do real se dissolvem na "platitude" da realidade empírica e na constituição da lógica e da matemática em sujeito universal do conhecimento. Por sua parte, as perspectivas biologistas sobre o conhecimento têm colocado a emergência de uma consciência ecológica, onde o sujeito do saber aparece como todo organismo biológico que internaliza e transforma seu meio ambiente. De forma paralela, tem aparecido uma série de teorias e metodologias que buscam a reintegração do conhecimento e de suas aplicações técnicas (a Teoria Geral de Sistemas).

O projeto positivista de unificação das ciências faz frente à crítica do logocentrismo 
da ciência moderna e seus impactos no ambiente, assim como à inevitável e necessária intervenção dos saberes não científicos na gestão ambiental. No entanto, a problemática da "articulação das ciências para a gestão ambiental" deve concentrar-se na análise de suas relações possíveis a partir das condições que impõe a própria estrutura paradigmática das ciências, de onde derivam os obstáculos epistemológicos à complementaridade e retotalização do campo do conhecimento, assim como suas possíveis relações interdisciplinares.

A necessidade de uma articulação científica só se justifica se existem processos materiais que, não podendo ser apreendidos a partir dos conhecimentos elaborados por uma só das ciências em seu estado atual, aparecem como regiões do real onde confluem os efeitos de duas ou mais ordens de materialidade, objeto de diferentes ciências. Essa articulação científica não pode ser pensada como uma fusão dos objetos teóricos das ciências - os que constituem sua especificidade teórica de onde derivam seu efeito de conhecimento -, senão como uma sobre-determinação ou uma interdeterminação dos processos materiais dos quais as ciências produzem um efeito de conhecimento em seus respectivos campos teóricos.

O problema da articulação entre ciências não se refere às aplicações técnicas do saber para resolver problemas práticos, nem às relações de um objeto científico com outros objetos empíricos. A articulação científica é um problema alheio às aplicações técnicas e ideológicas das ciências e diz respeito só a alguns casos de uma problemática transcientífica e intra-científica, da qual pode-se indicar as seguintes formas possíveis no campo ambiental:
a) A importação de conceitos provenientes de outras ciências para

serem trabalhados e transformados pelas necessidades internas do desenvolvimento do conhecimento da ciência importadora. Exemplo disso é o processo de importação das teorias da termodinâmica e da ecologia ao campo da economia, para reformular os conceitos de produção sustentável na economia ecológica (GEORGESCUROEGEN ,1971; COSTANZA, 1989; DALY, 1991; NAREDO, VALERO, 1999). De forma análoga, a construção de uma nova racionalidade produtiva tem implicado a reformulação de conceitos da economia (valor, recurso, desenvolvimento das forças produtivas, apropriação cultural) sobre a base de uma "aplicação" de teorias e conceitos da cultura, da ecologia e da tecnologia produtividade ecológica, produtividade eco-tecnológica, produtividade cultural; ecossistema-recurso, taxas ecológicas de exploração e uso de recursos, significado cultural da natureza, etc. - (LEFF, 1994). Esse seria um caso de trans-cientificidade teórica sem articulação científica.

b) A construção de categorias e conceitos integradores, onde podem ser articulados os conceitos de diferentes ciências. Dessa forma, a categoria de racionalidade ambiental articula as racionalidades teóricas, instrumental e prática onde confluem os conhecimentos, saberes e comportamentos que configuram o campo complexo do saber e da ação ambiental (LEFF, 1998). Por sua parte, o conceito de produtividade eco-tecnológica articula processos de diferentes ordens de materialidade, onde se integram as relações sociais de produção com as práticas produtivas, jurídicas, políticas e ideológicas nas que se integram processos de ordem ecológica, tecnológica e cultural. Essa articulação conceitual implica, por sua vez, a integração de processos diferentes na construção de um novo paradigma econômico, como um objeto de conhecimento científico "interdisciplinar". 
Assim, a produtividade sustentável aparece como a síntese de processos naturais, sociais, culturais e tecnológicos, cognitivos e identificáveis, que estabelecem os processos sinergéticos de um sistema produtivo ambiental complexo (LEFF, 1994).

c) A confluência dos efeitos de dois ou mais processos materiais, objeto de diferentes disciplinas, em um fenômeno empírico um sistema ambiental complexo -, que, ao não pertencer ao objeto de conhecimento de nenhuma de suas ciência, não implica a inclusão dos efeitos de um processo em outro nem a articulação dos conceitos de suas ciências. Este seria o fundamento teórico de uma problemática intercientífica, mas que não implica um processo de articulação teórica. Um exemplo disso são os estudos demográficos ou de fecundidade. As taxas de reprodução, assim como as características físicas e psicológicas da população, são o objeto de diferentes disciplinas. Nesses fenômenos convergem os efeitos de diversos processos determinados pela estrutura genética de uma população, por suas condições de adaptação biológica ao meio, pela demanda de força de trabalho que produz a dinâmica econômica, e pelo desejo de reprodução vinculado às formações do inconsciente, processos que são o objeto da biologia, da economia política e da psicanálise. Vários temas das etno-ciências são relacionados com esses processos interdisciplinares, nos quais a articulação contribui para desenvolver um campo mais complexo da demografia ou da etno-botância, mas não as estabelece como objetos científicos complexos (ver mais adiante o caso da biologia e da etno-botânica.)

d) A articulação dos efeitos de processos materiais, objeto de uma ou mais ciências, sobre processos que são objeto de outra ciência, o que implica uma determinação de processos externos que, se bem que não são absorvidos conceitualmente pela ciência afetada e não modificam o seu objeto de conhecimento, condicionam em tal grau os processos que analisa, que estes só podem entender-se como uma sobre determinação ou uma articulação dos efeitos dos processos objeto dessas ciências. Vários problemas da articulação natureza-sociedade exemplificam tal caso. A evolução e a sucessão dos ecossistemas naturais são objeto da biologia e da ecologia; mas os processos de transformação dos ecossistemas não dependem tão-somente das leis biológicas da evolução, senão que são afetados e sobredeterminados pela apropriação cultural e econômica dos recursos naturais. A racionalidade econômica não pode integrar-se no objeto da ecologia. Por ele, o estudo da transformação dos ecossistemas implica a articulação dos efeitos do modo de produção sobre os efeitos naturais e biológicos provenientes da estrutura funcional de cada ecossistema. Esse é um caso de sobredeterminação na articulação científica. Outro caso de articulação é o da organização cultural das formações sócioeconômicas "não capitalistas", objeto da antropologia e da etnologia. Nesse caso, articulam-se os efeitos do idioma, da organização dos ecossistemas que habitam e das estruturas sociais que constituem, na explicação de suas práticas produtivas e ideológicas. É um caso de codeterminação múltipla no processo de articulação.

Seguindo esses tipos de intercientificidade, pode-se afirmar que, para que exista articulação entre ciências em um sentido forte, é necessário que a materialidade de certo nível não seja mero apoio, pressuposição ou condição dos processos de outra ciência - por exemplo, o ser biológico do homem como suporte dos processos de trabalho ou de seus processos simbólicos -, a não ser que suas estruturas materiais tenham efeitos determinantes nos processos em que se articulam - por 
exemplo, os efeitos do modo de produção sobre os processos ecológicos, dos processos de significação nas formações ideológicas e na constituição de identidades. As estruturas biológicas, neuroniais e lingüísticas, que são condição da história, não se transformam com as mudanças históricas (ao menos não de forma imediata); mas a história sobredetermina os efeitos de suas estruturas: as formas simbólicas e discursivas em torno das formas de apropriação da natureza; a transformação ecossistêmica como efeito da acumulação de capital.

A articulação das ciências não se limita, então, a uma prática teórica consistente na importação de conceitos e paradigmas, ou a uma aplicação de objetos teóricos de um campo do conhecimento ao outro. Os objetos teóricos de cada ciência lhe dão sua especificidade e são intransferíveis, inaplicáveis. A articulação de ordens de materialidade do real - o que autoriza a pensar em uma articulação das ciências -, não surge dos pressupostos que explicam a gênese evolutiva e a emergência de novos níveis do real - a emergência da organização biológica a partir de suas bases físicas, ou da ordem simbólica e cultural como epifenômeno da ordem vital; tampouco se fundamenta nas impossíveis relações de constituição de uma ciência em outra. A articulação das ciências se dá como uma articulação dos efeitos dos processos materiais dos quais elas dão conta através de seus objetos de conhecimento. A necessidade de apreender esses processos em sua especificidade é o que obriga a reelaborar os conceitos teóricos de cada ciência e a produzir novos conceitos a partir do trabalho teórico sobre os conceitos importados de outras ciências, transformação que é mobilizada pelo sentido do saber ambiental externalizado pelas ciências. Isso leva a colocar a interdisciplinaridade ambiental, num sentido forte, como o processo de "colaboração" entre ciências que leva à fundação ou refundação do objeto teórico de diversas ciências, problematizadas pelo saber ambiental externo a seus paradigmas de conhecimento. $\mathrm{O}$ que leva, ao mesmo tempo, a questionar em que sentido o ambiente, ou os sistemas ambientais complexos, poderia ser considerado "objetos científicos interdisciplinares”.

Ressalte-se, de entrada, que a integração de conhecimentos e a confluência de diversos saberes nas diversas problemáticas socioambientais, não constituem só por esse fato objetos científicos interdisciplinares. $\mathrm{Na}$ maioria dos casos, tampouco se tem dado espaço para um trabalho teórico interdisciplinar, se está definido o processo interdisciplinar como o intercâmbio de conhecimentos que resulta em uma transformação dos paradigmas teóricos das disciplinas envolvidas; ou seja, em uma "revolução dentro de seu objeto" de conhecimento, ou até numa "troca de escala do objeto de estudo por uma nova forma de interrogá-lo” (CANGUILHEM, 1977).

A interdisciplinaridade ambiental entendida como a construção de um novo objeto científico a partir da colaboração de diversas disciplinas, e não só como o tratamento comum de uma temática - é um processo que tem sido consumado em poucos casos da história das ciências. São casos não generalizáveis para deduzir deles uma metodologia aplicável para produzir efeitos similares em outros campos do conhecimento e da pesquisa científica. Assim, especificada a problemática interdisciplinar no campo das relações teóricas da produção de conhecimentos - e não de suas aplicações práticas -, ela não deve confundir-se com a contribuição de um conjunto de conhecimentos nem com os diferentes saberes, técnicas e instrumentos que possibilitam diversas práticas de pesquisa e intervenção sobre o ambiente. 
A história das ciências da vida oferece um exemplo de interdisciplinaridade teórica no processo de reconstrução do objeto científico da biologia como a ruptura e reformulação do objeto teórico da biologia, ao conhecimento sobre a estrutura e as funções da matéria vivente. É assim que, a partir da construção do modelo de um cristal de DNA, foi possível a conjunção progressiva e coordenada dos resultados de várias disciplinas biológicas com os da genética formal. A citologia, a microbiologia e a bioquímica para começ ar. Mas essa conjunção não foi fecunda a não ser na medida em que a justa posição dos resultados comandava a refundição das relações entre as disciplinas que os tinham proporcionado 9 .

Existem muitos exemplos de estudos interdisciplinares nos quais concorrem especialidades provenientes de diferentes campos científicos. Um caso ilustrativo é o da etno-botânica, onde intervem a ecologia para explicar as condições naturais de produção e regeneração do meio vegetal; as disciplinas

\footnotetext{
${ }^{9}$ Certamente, esta refundição interdisciplinar não teria sido possível sem a assimilação transdisciplinar da teoria da informação e da cibernética ao campo da biologia, assim como por uma série de avanços da experimentação científica e do instrumental de investigação. Sem o estudo das estruturas cristalinas por difração dos raios-x, sem a microscopia eletrônica, sem o emprego de radioisótopos, teria sido impossível empreender o conjunto de pesquisas que permitiram, no final, localizar nas macromoléculas do ácido desoxirribonucléico a função conservadora e a função inovadora da herança... Este novo objeto da biologia situa-se na interseção das técnicas de macroextração e de microdissecção, da álgebra combinatória, do cálculo estatístico, da óptica eletrônica, da química das enzimas. Mas o novo objeto biológico tem por correlato uma nova biologia, uma biologia nascida do trabalho que foi engendrado a seu objeto... A constituição deste novo objeto de biologia (aparece como) um objeto poli-científico ou inter-científico (entendido não como) um objeto tratado em comum por diversas disciplinas, senão (como) um objeto construído expressamente como efeito de sua colaboração. (CANGUILHEM, 1977).
}

etnológicas (etno-tecnologia, etno-ecologia e etno-lingüística), para explicar o processo cultural de aproveitamento dos recursos do meio; a antropologia ecológica, para dar conta do condicionamento ecológico sobre a organização social e produtiva das culturas; a antropologia estrutural, para explicar o sistema de representações de uma cultura sobre seu meio e, portanto, a significação de seus vegetais; as disciplinas históricas, para explicar os processos de transculturação que afetam as práticas produtivas e a utilização dos recursos dos povos; enfim, a história econômica recente e a análise do sistema econômico dominante, para dar conta das determinações que impõem as condições de valorização e exploração dos recursos sobre as práticas tradicionais de reconhecimento e aproveitamento de seu ambiente ${ }^{10}$.

No entanto, se bem que a etno-botânica delimite uma problemática no espaço das possíveis relações entre ecologia, cultura, história e economia, ela resulta em um processo interdisciplinar menos "forte" do que o da biologia genética, tanto que seu objeto constitui-se como um campo de aplicação de diferentes ciências nas quais não se estabelece uma transformação de seus objetos de conhecimento.

Vê-se o quanto distante desses princípios da interdisciplinaridade científica está o projeto constituído pela colaboração de umas supostas "ciências ambientais", projeto encarregado de analisar o campo generalizado das relações sociedade-natureza. A própria história das ciências tem mostrado a impossível generalização dos objetos científicos e

\footnotetext{
${ }^{10}$ BARRAU, J. L'ethnobotanique au carrefour des sciences naturelles et des sciences humaines, Bull. Soc. Bot. Fr., n. 118, p. 242, 1971. e LEFF, E. Ethnobotanics and anthropology as tools for a cultural conservation strategy. In: MCNEEDY, J. A.; PITT, D. (Eds.). Culture and conservation. Worcester: Billing and Sons, 1985.
} 
dos campos de produção de conhecimentos, assim como a aplicação de um método totalizador e geral (o materialismo dialético ou o estruturalismo genético). Por sua vez, a problemática ambiental tem colocado em evidência a posição de externalidade e exclusão de um conjunto de disciplinas na explicação e resolução dos problemas ambientais, assim como os obstáculos que os paradigmas científicos apresentam para reorientar suas preocupações teóricas, seus instrumentos de análise e seus métodos de pesquisa para um objetivo comum constituído pelo meio ambiente.

O ambiental aparece como um campo de problematização do conhecimento, que induz um processo desigual de "internalização” de certos princípios, valores e saberes "ambientais" dentro dos paradigmas tradicionais das ciências. Tal processo tende a gerar especialidades ou disciplinas ambientais, métodos de análise e diagnóstico, assim como novos instrumentos práticos para normatizar e regular o processo de desenvolvimento econômico sobre bases ambientais. No entanto, essa orientação "interdisciplinar” para objetivos ambientais não autoriza a constituição de um novo objeto científico - o ambiente - como domínio generalizado das relações sociedade-natureza.

Podemos, inclusive, identificar um conjunto de temas e problemáticas ambientais que se apresentam como problemas contraparadigmáticos, no sentido de que encontram as vias fechadas para a complementaridade interdisciplinar. Exemplos desses encontram-se na "confrontação" entre economia e ecologia, onde a racionalidade econômica de curto prazo impede internalizar as temporalidades e os ciclos ecológicos que asseguram a renovação da natureza e a sustentabilidade do desenvolvimento. Assim mesmo, temas como o da qualidade de vida se apresentam como problemas ambientais antiparadigmáticos, no sentido de que suas próprias características implicam racionalidades e valores que estão fora dos princípios de quantificação, de objetividade, de universalidade, de unidade e de medição que pretendem as ciências "normais".

Não é fácil, porém, abandonar a tendência de pensar o ambiente como um campo de atração e convergência do conhecimento, de submissão das ciências frente a um propósito integrador. O meio tem sido, afinal de contas, uma rede de relações capaz de captar todo saber em busca de seu objeto; ele dá forma onde se dissolve o excedente de saber que transborda do conhecimento científico abrindo o campo do saber ambiental.

\section{Da interdisciplinaridade ao diálogo de saberes}

A problemática ambiental tem transbordado o campo dos paradigmas científicos e do conhecimento disciplinar. Por um lado, a problemática ambiental é conseqüência das formas de conhecimento do mundo, da objetivação da realidade e o domínio da natureza através da imposição de um logos, de uma razão na qual não só os valores têm sido marginalizados e subjugados, como também têm sobrexplorado a natureza e o homem em um afã dominador e produtivista. Em conseqüência, a sustentabilidade não será um fim alcançável através de uma reintegração interdisciplinar do conhecimento como fundamento de uma gestão científica do desenvolvimento, e menos ainda de uma "economização" e mercantilização da natureza.

A abertura do cerco epistemológico das ciências ao diálogo de saberes na complexidade ambiental não responde a uma vontade anarquizante para flexibilizar e relativizar o conhecimento (FEYERABEND, 1982); 
não é um desconhecimento e um abandono do poder do conhecimento de onde geram as ciências. $\mathrm{O}$ reconhecimento do saber ambiental fica, assim, externalizado, e a gestão ambiental implica a confluência e a aplicação de saberes que transbordam o campo do conhecimento científico. É o convencimento de que não será possível resolver a crise ambiental mediante uma administração científica da natureza, já que toda intervenção e apropriação da natureza implica estratégias de poder no saber (LEFF, 1998). É, por sua vez, a certeza de que a gestão ambiental não será alcançável pela atomização e autonomia dos saberes locais; que a geração de capacidades locais está se dando através de uma hibridização dos conhecimentos científicotecnológicos e dos saberes práticos "tradicionais”. A natureza é administrada, explorada, conservada, transformada, através de formas de valorização e de significação que provêm da cultura. O que está em jogo nas estratégias de poder em torno da conservação ecológica no processo de globalização é a confrontação da via marcada pela apropriação científica e a valorização mercantil (os direitos de propriedade intelectual e econômica), frente aos diversos significados culturais atribuídos à natureza. A gestão ambiental num regime democrático implica uma gestão participativa da população no processo de produção. A encruzilhada pela sustentabilidade é uma disputa pela natureza e uma controvérsia pelos sentidos alternativos do desenvolvimento sustentável. Ela faz com que a sustentabilidade tenha como condição inevitável a participação dos atores locais, de sociedades rurais e comunidades indígenas, a partir de culturas, seus saberes e suas identidades.

Nessa perspectiva, a interdisciplinaridade ambiental transborda o campo científico, acadêmico e disciplinar do conhecimento formal certificado, e se abre a um diálogo de saberes, onde se dá o encontro do conhecimento codificado das ciências com os saberes codificados pela cultura. A abertura para o diálogo de saberes não só é uma hermenêutica que multiplica as interpretações e os sentidos do conhecimento; não é uma tecnologia que multiplica os campos aplicativos do conhecimento. É o caminho de uma interdisciplinaridade marcada pelo propósito de retotalização sistêmica do conhecimento, a um saber marcado pela diversidade de saberes e pela diferenciação dos sentidos do ser.

O saber ambiental é externo ao conhecimento objetivante que impulsiona coisificação do mundo; mas também toma distância do diálogo introspectivo que fala com seus próprios fantasmas, que incita a liberação íntima do sujeito. É um saber que leva a ressignificar os sentidos existenciais e a reconfigurar identidades individuais e coletivas e, ao mesmo tempo, a reconstruir o mundo objetivo, a realidade que é produzida pelo saber.

A complexidade ambiental irrompe neste momento, marcando a ruptura da modernidade e a pós-modernidade. A própria modernidade, em seu afã unificador, universalizante e homogeneizador, vai gerando em suas rupturas sua abertura à diferença; vai forjando o germe da heterogeneidade, das diversas ordens e dos distintos tempos. É nesse processo no qual as racionalidades articuladas, que fundam e se reforçam para gerar o regime globalizante da modernidade, dão lugar em seu seio à emergência do modernismo na arte, como uma tendência que procura desprendimento da tradição e uma revolução permanente da novidade (que leva à multiplicação das modas e do consumo), da democracia que busca a igualdade, enfrentando as hierarquias de uma sociedade estratificada e normalizada e que, ao mesmo tempo, reforça a emancipação pessoal do sentido e do 
individualismo contemporâneo, abrindo as comportas para a era do vazio e para a cultura da pós-modernidade (LIPOVETSKY, 1986).

Nesse sentido, e no próprio seio do logocentrismo que configura o projeto positivista, a episteme das ciências modernas estabelece um regime de domínios diferenciados do conhecimento - ciências formais e empíricas; ciências da matéria, da vida e da cultura (FOUCAULT, 1969). A sociedade democrática moderna rompe também com a complexidade homogênea das sociedades tradicionais para produzir uma diferenciação e heterogeneidade de suas ordens internas, baseadas em lógicas contraditórias - hedonismo, eficácia, igualdade - (BELL, 1979), assim como articulação/desarticulação das ordens tecnoeconômica, política e cultural, com suas racionalidades e temporalidades diferenciadas, como o colocaram em seu tempo Marx e Weber em suas análises da articulação de instâncias e racionalidades na sociedade capitalista.

O saber ambiental transborda o campo estabelecido por um regime do logos modernizador que legitima a racionalidade unificante e a ordem disciplinar do conhecimento objetivo. Assim sendo, implica um rompimento com o conhecimento universal e disciplinar que implanta o regime de dominação da natureza através da ciência e que se situa acima dos saberes e identidades culturais. Mas o saber ambiental não suplanta o regime de socialização disciplinar do conhecimento pela individuação do saber "pessoal". O saber ambiental é um saber identificável, conformado por e arraigado em identidades coletivas que dão sentido a racionalidades e práticas culturais diferenciadas.

O diálogo de saberes não é um relaxamento do regime disciplinar na ordem do conhecimento para dar lugar à aliança de lógicas contraditórias, a abertura de um jogo indiferente de linguagens, a um consumo massificado de conhecimentos, ou de uma personalização subjetiva e individualizada do conhecimento, capazes de coabitar com suas contradições. O saber ambiental se forja no encontro (enfrentamento, entrecruzamento, hibridização, antagonismo) de saberes diferenciados por matrizes de racionalidadeidentidade-sentido que respondem a estratégias de poder pela apropriação do mundo e da natureza ${ }^{11}$.

A atomização do social e o fracionamento do conhecimento não são reintegráveis por um método sistêmico, por um método interdisciplinar ou pelo livre mercado. Não é uma reunificação e homogeneização consertadas num regime de diferenças sem substância. O esvaziamento de sentido de sujeitos e "eus" sem substância e equiparáveis, é o correlato ao esvaziamento ontológico da teoria geral de sistemas, obcecado pelas homologias estruturais do conhecimento formal. A racionalidade ambiental confronta, assim, o logocentrismo da ciência positivista, a racionalidade formal e instrumental da modernidade e o projeto de interdisciplinaridade teórica e técnica que busca recompor essa lógica fundacional da civilização moderna. A racionalidade ambiental chama à construção de um saber fundado em uma constelação de diversidades arraigadas na cultura e na identidade.

Ao final dessa busca da humanidade de nomear, codificar e tocar o real; de apreender, compreender e dominar a natureza; de soletrar o infinito; logo, de todo esse périplo pelo mundo da gramática, das ciências, da

\footnotetext{
${ }^{11}$ Como afirma Lyotard, (1969). "O vínculo social é de linguagem, mas não está feito de uma fibra única. É uma textura onde se entrecruzam (...) um número indeterminado de jogos de linguagem que obedecem a regras diferentes ... Não existe na ciência uma meta-linguagem geral dentro da qual todos as demais possam ser transcritas e avaliadas.”
} 
hermenêutica, as pessoas se encontram sendo pensadas por outro, pelo conhecimento com um outro, externo, que pensa o ente e se pensa, mas não compreende o ser; que deixa nus frente ao saber e ávidos de sentido. Talvez seja a angústia, frente ao esvaziamento dos sentidos existenciais, e essa sede de vida a qual expressam tanto as lutas das etnias pela reafirmação de suas identidades, como o drama desse ser solitário, cujo grito provém da angústia frente uma metafísica, um logos, uma gramática e uma epistemologia; de um verbo e um tempo que nos pensa, nos impõe sua verdade e nos sujeita:

“... não podes pensar o infinito... Mas pensa que podes sofrê-lo porque ele pensa em ti, te pensa sem cessar... E isto não é mais que o começo, o mero começo do começo. És pensado. E porque és pensado tu deves pensar que tu pensas. Tu deves; não podes escapar. Só que têm uma margem entre o pensamento que te pensa e o que tu pensas que pensas. ... Faz falta uma estrela para ver a escuridão? ... Que é o uso do tempo? Fornicação perpétua com $o$ verbo eterno. Engendrando o momento da verdade. Irrupção pontual na duração, relâmpago de um presente mais além de toda gramática, revelação das palavras como matéria milagrosa, da língua como lugar e vínculo de transubstanciação. Todo nome é uma assinatura em branco ... todas essas linguagens estranhas, essas singulares construções gramaticais. Línguas? Regras? ... Normas, máximas, preceitos; modelos, funções, equações; postulados, teoremas, corolários ...; protocolos, métodos, propriedades, sistemas; leis, fórmulas, nomenclaturas, etc., louco carrossel que gira, gira, gira... Até quando? Com que finalidade? E a que preço? Palavras que remetem sem repouso, de uma a outra, e que parecem tender à mesma significação inefável, cascata de palavras que se regulam por si sós, formando um colar em volta de uma lei secreta, não expressa, talvez inexpressivel, talvez infernal, estas palavras que compõem uma sarabanda, uma chamando a outra e a outra à seguinte e te arrastam em um baile, até uma certa consumação, esperança de terminação, de satisfação, sim, estas palavras que se esgarçam como prometendo a paz interior e a paz social ... enfim, a paz verdadeira, a que se realiza quando o espírito humano - se é que ainda existe algo semelhante -pode estar seguro de haver embarcado nesse trem automaticamente programado, tão conhecido, tão reconhecível, a tal ponto que se chama "o conhecimento", que farsa! Solicitar, reunir, demonstrar. Estas palavras tão cativantes, tão niilistas, tão adormecedoras por sua aptidão para a uniformidade, estas palavras, ao fim e ao cabo, são semelhantes, tão semelhantes e intercambiáveis como parecem ser? Semelhantes... talvez para fazermos semelhantes? Na verdade semelhantes ... Idênticos, sinônimos, similares, analógicos? Ou então pastiches, simulacros, embustes? Reproduções, fac-símiles, réplicas? Ou então imitações, mímicas, paródias, fantasias, caricaturas, plágios?... Inclusive falsificações, simulações, embustes e, portanto, ilusões, mentiras, mistificações. Isomorfas, isotermas, isóbaras! Equivalentes, eqüiláteras, equívocas ... Oh, grandiosa e grotesca estafa da língua que joga conosco quando nós cremos usá-la!. (ANDRÉ, 2000)

É nessa ruptura, nesse limite, nessa desconstrução do logos, nessa sacudida e nesse desencadeamento do poder imposto pelo conhecimento, que o propósito da interdisciplinaridade se abre para a reconstrução do saber, na via da reconstituição das identidades e o diálogo com outros saberes, na construção de um futuro aberto até o infinito, a "alteridade" e a alternativa.

Versão do espanhol para o português por Maria del Carmen S.Lopez e revisado por Attilio Brunacci e Daniel Joseph Hogan. 


\section{Referências}

ANDRÉ, S. Flac. México: Siglo XXI Editores, 2000.

APOSTEL, L. et al. Interdisciplinariedad: problemas de la enseñanza y de la investigación en las universidades. México: ANUIES; 1975.

BACHELARD, G. La formación del espíritu científico. México: Siglo XXI, 1938.

BALIBAR, E. Nombres y lugares de la verdad. Buenos Aires: Ediciones Nueva Visión, 1995.

BELL, D. Les contradictions culturelles du capitalisme. Paris: PUF, 1979.

BERTALANFFY, L. V. Teoría general de los sistemas. México: FCE, 1968.

BOOKCHIN, M. The philosophy of social ecology: essays on dialectical naturalism. Montreal: Black Rose Books, 1990.

BÖHME, G., et al. Finalization in science. Soc Sci Inform, v.15, p.307-330, 1976.

CANGUILHEM, G. Idéologie et rationalité dans l'histoire des sciences de la vie. Paris: Librairie Philosophique J. Vrin, 1977.

CARVALHO, I. Hermenéutica y educación ambiental. In: LEFF, E. (Coord.). La complejidad ambiental. México: Siglo XXI, 2000.

COSTANZA, R. What is ecological economics. Ecol Econ., v.1, p.1:1-7, 1989.

DALY, H. Steady-state economics. Washington: Island Press, 1991.

DERRIDA, J. De la gramatología. México: Siglo XXI, 1967.

Márgenes de la filosofía. Madrid:

Cátedra; 1989.
ESCOBAR, A. Cultural politics and biological diversity: state, capital and social movements in the Pacific Coast of Colombia. Colombia; 1997. [mimeo]

- The place of nature and the nature of place: local knowledge and alternative worlds. In: SIMPOSIUM ON ETHNOBOTANICS AND EPISTEMOLOGY, 2, International Congress on Ethnobotanics; 1997 Oct 12-7.

- After nature: steps to an antiessentialist political ecology. Curr. Anthropol, v.40, n.1, 1999.

FERNÁNDEZ, R. El saber ambiental: marco para una agenda de estudios de postgrado. Formación Ambiental, v.11, n.24, p.18-22, 1999.

FEYERABEND, P. La ciencia en una sociedad libre. Madrid: Siglo XXI, 1982.

FLORIANI, D. Interdisciplinariedad: teoría y práctica en la investigación y en la enseñanza. Formación Ambiental, v.10, n.23, p.17-21, 1998.

FOLLARI, R. Interdisciplinariedad. México: UAM-Azc., 1982.

FOUCAULT, M. L’archéologie du savoir. Paris: Gallimard, 1969.

Power/knowledge. New York: Pantheon Books, 1980.

FUNTOWICZ, S.; RAVETZ, J. Epistemologia política: ciência com la gente. Buenos Aires: Centro Editor de América Latina, 1993.

systems. Futures, v.26, n.6, p.558-68, 1994.

FUNTOWICZ, S.; MARCHI, B. Ciencia post-normal, complejidad reflexiva y sustentabilidad. In: LEFF, E. (Coord.). La complejidad ambiental. México: Siglo XXI, 2000. 
GARCÍA, R. Conceptos básicos para el estudio de sistemas complejos. In: LEFF, E. (Coord.). Los problemas del conocimiento y la perspectiva ambiental del desarrollo. México: Siglo XXI, 1986.

GARCÍA, R. Interdisciplinariedad y sistemas complejos. In: LEFF, E. (Coord.). Ciencias sociales y formación ambiental. Barcelona: GEDISA/UNAM/PNUMA, 1994.

HARAWAY, D. Simians, cyborgs and women: the reinvention of nature. New York: Routledge, 1991.

Meets onco mouse. New York: Routledge, 1997.

JACOBI, P. Ciência ambiental: os desafios da interdisciplinaridade. São Paulo: Programa de Pós Graduação em Ciência Ambiental da USP, 1999.

JOLLIVET, M. Sciences de la nature, sciences de la société: les passeurs de frontières. Paris: CNRS Editions, 1992.

KUHN, T. The structure of scientific revolutions. Chicago: The University of Chicago Press, 1962.

LEFF, E. Sobre la articulación de las ciencias en la relación naturaleza sociedad. In: . (Ed.). Biosociología y articulación de las ciencias. México: UNAM, 1981.

. Ambiente y articulación de ciencias. In: LEFF, E. (Coord.). Los problemas del conocimiento y la perspectiva ambiental del desarrollo. México: Siglo XXI, 1986.

Sociología y ambiente. In: LEFF, E. (Coord.). Ciencias sociales y formación ambiental. Barcelona: GEDISA/UNAM/ PNUMA, 1994.

Saber ambiental: sustentabilidad, racionalidad, complejidad, poder. México: Siglo XXI/UNAM/PNUMA, 1998.
La racionalidad ambiental y el fin del naturalismo dialéctico. Persona Sociedad, (n. esp.), marzo, 1999.

Pensar la complejidad ambiental. In: LEFF, E. (Coord.). La complejidad ambiental. México: Siglo XXI/UNAM/ PNUMA, 2000.

. (Coord.). Los problemas del conocimiento y la perspectiva ambiental del desarrollo. México: Siglo XXI, 1986.

(Coord.). Ciencias sociales $\mathbf{y}$ formación ambiental. Barcelona: GEDISA/ UNAM/PNUMA, 1994.

\section{La complejidad ambiental.} México: Siglo XXI/UNAM/PNUMA, 2000. (Colección Aprender a Aprender)

LICHNEROWICS, A. Matemáticas e interdisciplinariedad. In: APOSTEL, L. Interdisciplinariedad: problemas de la enseñanza y de la investigación en las universidades. México: ANUIES, 1975.

LIPOVETSKY, G. La era del vacío. Barcelona: Anagrama, 1986.

LYOTARD, J. F. La condition postmoderne. Paris: Les Editions du Minuit, 1979.

MARCUSE, H. El hombre unidimensional. Barcelona: Seix Barral; 1968. MEADOWS, D. et al. Los límites del crecimiento. México: FCE; 1972.

MORIN, E. Le paradigme perdu: la nature humanine. Paris: Editions du Seuil; 1973.

. La méthode: la nature de la nature. Paris: Editions du Seuil; 1977.

. La méthode: la vie de la vie. Paris: Editions du Seuil; 1980.

La méthode: la connaissance de la connaissance. Paris: Editions du Seuil; 1986. 
Introducción al pensamiento de la complejidad. Barcelona: GEDISA, 1993. MOSS, R. The integration of teaching on environmental education. Paris: Universities and Environmetal Education/ UNESCO, 1986.

NAREDO, J. M.; VALERO, A. (Dirs.). Desarrollo económico y deterioro ecológico. Madrid: Fundación Argentaria; 1999. (Colección Economía y Naturaleza)

NOVO, M.; LARA, R. El análisis interdisciplinar de la problemática ambiental. Madrid: UNED/Fundación Universidad Empresa/UNESCO/PNUMA; 1997. 2v.

PNUMA. Diagnóstico de la incorporación de la dimensión ambiental en los estudios superiores de América Latina y el Caribe. México, 1985. (UNEP/WG. 138/Info. 3).

Directorio de instituciones y programas de formación ambiental de América Latina y el Caribe. México, 1995.

PNUMA/UNESCO. Universidad y Medio Ambiente en América Latina y el Caribe. Seminario de Bogotá. México: PNUMA/ ICFES/Universidad Nacional de Colombia; 1988.

PRIGOGINE, I.; STENGERS, I. La nouvelle alliance: métamorphose de la science. Paris: Gallimard, 1979. ; Order out of caos: man's new dialogue with nature. New York: Bantam Books, 1984.

PRIGOGINE, I. El fin de las certidumbres. Madrid: Taurus, 1997.

RAPPAPORT, R. A. The flow of energy in an agricultural society. Sci Am., v.224, n.3, 1971.
UNESCO. La educación ambiental: las grandes orientaciones de la Conferencia de Tbilisi. Paris, 1980.

UNESCO. Universities and environmetal education. Paris, 1986.

UNESCO/UNEP. Interdisciplinary approaches in environmental education. Paris, 1985. (Environmental Education Series Núm., 14).

VATTIMO, G. L'éducation contemporaine, entre l'épistémologie et l'herméneutique. Entre savoirs l'interdisciplinarité en acte: enjeux, obstacles, résultats. París: Erès; 1992. (cit. in Zanoni y Raynaut, op. cit.).

WILSON, E. O. Sociobiology: the new synthesis. Cambridge: The Belknap Press of Harvard University Press, 1975.

ZANONI, M.; RAYNAUT, C. Meio ambiente e desenvolvimento: imperativos para uma pesquisa e a formação? Reflexões em torno do doutorado da UFPR. Cadernos de Desenvolvimento e Meio Ambiente, n.1, 1994.

Enviado em: 10/12/2011

Aceito em: 14/12/2011 